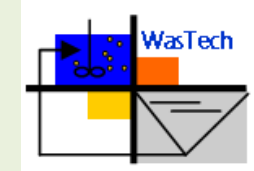

\title{
Biodiesel Production from Microalgae by Extraction - Transesterification Method
}

\author{
Nguyen Thi Phuong Thao, Nguyen Thanh Tin \& Bui Xuan Thanh* \\ Faculty of Environment, Ho Chi Minh City University of Technology (HCMUT), Vietnam. Building B9, 268 Ly Thuong Kiet \\ Street, District 10, Ho Chi Minh City, Viet Nam. E-mail: bxthanh@hcmut.edu.vn
}

\begin{abstract}
The environmental impact of using petroleum fuels has led to a quest to find a suitable alternative fuel source. In this study, microalgae were explored as a highly potential feedstock to produce biodiesel fuel. Firstly, algal oil is extracted from algal biomass by using organic solvents (n-hexan). Lipid is contained in microalgae up to $60 \%$ of their weight. Then, Biodiesel is created through a chemical reaction known as transesterification between algal oil and alcohol (methanol) with strong acid (such as $\mathrm{H}_{2} \mathrm{SO}_{4}$ ) as the catalyst. The extraction - transesterification method resulted in a high biodiesel yield (10\% of algal biomass) and high FAMEs content (5.2\% of algal biomass). Biodiesel production from microalgae was studied through experimental investigation of transesterification conditions such as reaction time, methanol to oil ration and catalyst dosage which are deemed to have main impact on reaction conversion efficiency. All the parameters which were characterized for purified biodiesel such as free glycerin, total glycerin, flash point, sulfur content were analyzed according to ASTM standard
\end{abstract}

Key words - Biodiesel, microalgae, extraction - transesterification, fatty acid methyl esters (FAMEs),

ASTM standard Doi: http://dx.doi.org/10.12777/wastech.1.1.2013.6-9

Citation: Thao, N.T.P., Tin, N.T., and Thanh, B.X. 2013. Biodiesel Production from Microalgae by Extraction - Transesterification Method. Waste Technology 1(1):6-9. Doi: http://dx.doi.org/10.12777/wastech.1.1.2013.6-9

\section{Introduction}

World faces the progressive depletion of its energetic resources mainly based on non-renewable fuels. Thus the unprecedented increase in energy consumption drives the rising petroleum fuel cost. In addition, the intensive utilization of fossil fuels has led to the increase in the generation of polluting gases released into the atmosphere, which have caused changes in the global climate. The solution to this issue depends on how the development and implementation of technologies based on alternative sources of energy will be undertaken. Through the use of renewable energetic resources, humankind can find part of the solution to their energy requirements in an environmentally friendly way.

One renewable solution is the use of solar energy in form of biomass (bioenergy). Conversion of these feedstock into biofuels is an important choice for the explosion of alternative energy sources and reduction of polluting gases. Microalgae are currently considered to be one of the most promising alternative and renewable feedstock sources for biofuels. In recent years, the "algae for fuel" concept has gained renewed interest with energy prices fluctuating widely (Chisti, 2007; Hu et al, 2008). Not only the oil content in microalgae is slightly higher than that in other terrestrial plants, but also the algal biomass productivity is by far the highest.

In the algal biodiesel processes, fatty acid methyl esters (FAMEs), the chemical composition of biodiesel, are commonly created by transesterification of algal oil with methanol using strong acid sulfuric $\left(\mathrm{H}_{2} \mathrm{SO}_{4}, 98 \%\right)$ as a catalyst and n-hexane as a solvent. Different from terrestrial oil feedstock (such as palm, soybean or canola seed), algal oil is easily extracted from algal cell by crushing followed with solvent extraction. Mechanical crushing of algal biomass also can be used but it is really difficult to extract algal oil with the existing equipment.

There are several methods to prepare biodiesel from algal biomass (such as oil extraction from algal biomass by transesterification and direct transesterification from algal biomass (Johnson, 2009). Most extraction methods are based on method which was developed by Bligh and Dryer in 1959 (Lewis et al, 2000). There are a number of steps producing biodiesel from microalgae. Firstly, the oils were extracted from algal biomass through a number of ways. The least expensive extraction is simply though cold 
pressing (Johnson, 2009). Up to $70 \%$ of the oil contained within the algae can be extracted this way (Danielo, 2005). The use of organic solvent can increase this extraction level to $99 \%$, but there is an increased cost in processing to achieve this (Metzger and Largeau, 2005).

In this study, extraction - transesterification method was used as a main way to produce biodiesel fuel from algal biomass. More specifically, this paper also focused on transesterification conditions such as reaction time, the methanol to oil ration, catalyst loading which have important role on transesterification reaction conversion efficiency.

\section{Materials and experiment methods}

\subsection{Materials}

Algae grow in most aquatic environment and need a light source, carbon dioxide, water and inorganic to create biomass. The growth medium must contain essential nutrients such as nitrogen, phosphorus, iron and sometimes silicon (Grobbelaar, 2004). In this study, algae are cultivated in pilot - open pond by domestic wastewater in Ho Chi Minh City. Algal have ability to treat many contaminants, but have proven to be great options when nutrients such as nitrogen $(\mathrm{N})$ and phosphorus (P) need to be eliminated. The percentage of nitrogen and phosphorus reduction was $89.47 \%$ and $86.87 \%$ respectively. Biomass purity and productivity were affected by contamination with unwanted algal species and organisms that feed on algae. To harvest algae from this dilute solution, algal cells in solution are usually concentrated by sedimentation; the condensed slurry is then centrifuged at $4000 \mathrm{rpm}$ for 15 minutes to further remove water. After centrifugation, the water content of the wet biomass was $80 \%$. Depending on the experimental design in this study, the cell pellets were wet biomass.

Algal biomass contains three main components: carbonhydrates, protein and lipids/natural oil. Because the bulk of the natural oil made by microalgae is in the form of triacylglycerides (TAGs) which is the right kind of oil for producing biodiesel, microalgae is the exclusive focus in the algae - to - biofuel arena (Danielo, 2005). The fatty acids attached to the TAG within the algal cells can be both short and long chain hydrocarbons. The shorter chain length acids are the idea for the creation of biodiesel, and some of the longer ones can have other beneficial uses.

For the extraction - transesterification method, Methanol, n-hexane, sulfuric acid $\left(\mathrm{H}_{2} \mathrm{SO}_{4}\right)$, sodium chloride and other chemicals were purchased from Bach Khoa Co. Ltd (Ho Chi Minh, Viet Nam).

\subsection{Method}

The algal oil extraction procedure was adapted from the protocol described by Bligh and Dryer in 1959. Freeze dried algal biomass $(10 \mathrm{~g})$ or wet biomass (with $10 \mathrm{~g}$ dry weight equivalent) was placed in the glass vial. Organic solvent (n-hexane) and methanol were then added to the glass. The mixture was blended for 5 minutes, and then transferred to centrifuge tubes. After that, glass was washed twice by solvent and distilled water respectively. These mixtures also were added to the tube. The contents were then centrifuged at $4,000 \mathrm{rpm}$ for 15 minutes. The organic layer containing algal oil was collected and transferred to a pre - weighed glass vial.

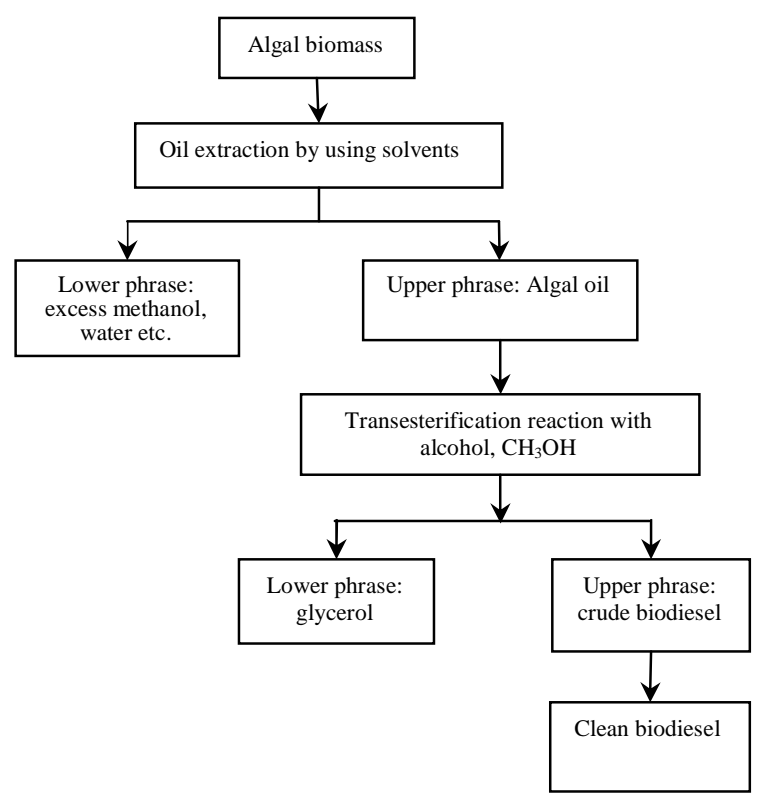

Fig.1 Schematic diagram showing the experimental steps typically undertaken for laboratory - scale production of microalgae biodiesel using an organic solvent mixture as a lipid extraction

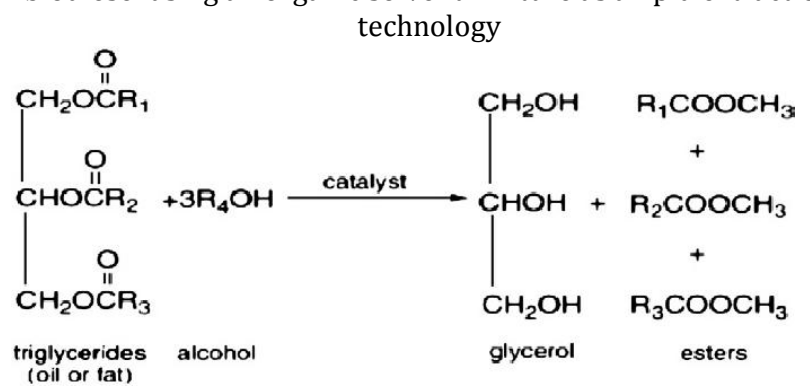

Fig. 2 Acid - catalyzed transesterification of triglycerides

The algal oil was heated at $75^{\circ} \mathrm{C}$ for 5 minutes to evaporate water content. A mixture of methanol, sulfuric acid and solvent (n-hexane) was added to the algal oil, and then the reaction mixture was blended for 35 minutes at a temperature of $75^{\circ} \mathrm{C}$. After the reaction was completed, the samples were cooled down to room temperature, the crude ester layer (the upper phase) was separate from glycerol layer in a separating funnel. The raw ester layer contained methyl ester, possibly un-reactive oil, methanol and glycerol. To separate methanol, the organic layer was washed two times with distilled water in separating funnel 
until the washings were neutral. The FAMEs layer was dried by using $\mathrm{NaCl}$ solution. The upper phase containing FAMEs was collected and transferred to a pre-weighed glass test tube. The solvent was removed by using Rotary Evaporator at $320 \mathrm{mbar}$ and $36^{\circ} \mathrm{C}$. After $\mathrm{n}$-hexane eliminated, the composition of FAMEs contained in the crude biodiesel fuel was analyzed by gas chromatograph (GC). According to theory, the transesterification requires $3 \mathrm{~mol}$ of alcohol per one mol of triglyceride to produce $3 \mathrm{~mol}$ of fatty acid methyl esters and $1 \mathrm{~mol}$ of glycerol. Excess alcohol was used to keep reaction volume consistent and result in higher ester yield. In this study, we investigated the role of substrate ratio in transesterification reaction in solvent - free medium. Firstly, the reaction was conducted in 20, 25, 30, 35 and 45 minutes at $75^{\circ} \mathrm{C}$. After the effect of reaction time was determined, It is continued conducting the reaction at $3: 1,3.2: 1,3.4: 1,3.6: 1$ and 3.8:1 methanol to dry algal biomass (vol./wt.) ratios at $75^{\circ} \mathrm{C}$ and the most effective reaction time. Finally, the effect of catalyst loading on algal biomass conversion efficiency at 0.5:1, 0.55:1. 0.6:1, 0.65:1 and $0.7: 1$ catalyst $\left(\mathrm{H}_{2} \mathrm{SO}_{4} 98 \%\right)$ to dry biomass (vol./wt.) ratios were also discussed.

\subsection{Gas - chromatography analysis}

The biodiesel sample was taken to analyze the purity by gas chromatography (agilent 6890), equipped with an HP Innowax capillary column $(30 \mathrm{~m} \times 0.25 \mathrm{~mm})$ and a flame ionization detector (FID). Nitrogen was used as the carrier gas at a constant flow rate of $20 \mathrm{~mL} / \mathrm{min}$. The column oven temperature was programmed from 50 to $130^{\circ} \mathrm{C}$ (at the rate of $20^{\circ} \mathrm{C} / \mathrm{min}$ ) and held at $130^{\circ} \mathrm{C}$ for $5 \mathrm{~min}$, then raised to $260^{\circ} \mathrm{C}$ at $2.5^{\circ} \mathrm{C} / \mathrm{min}$ and maintained at this temperature for $10 \mathrm{~min}$.

\section{Results and Discussion}

\subsection{Effect of reaction time}

Effect of reaction time on procedure of biodiesel from microalgae is shown in Fig. 3. The methyl ester yield increased as the length of reaction time was increased. More specifically, the FAMEs content in biodiesel increased dramatically from 20-min to 35 -min reaction time, after that, the FAMEs yield kept rising very slowly and then practically constant above $5.2 \%$ at $45 \mathrm{~min}$. The reaction approved to be in equilibrium is the reason why the rate rose quite slowly. The results indicate that the biodiesel quality (heating value, based on FAMEs content) at 35minute reaction time is significantly higher than that in others.

\subsection{Effect of methanol to dry algal biomass ratio}

The ratio of methanol to oil is one of the most important variables that affects conversion efficiency as well as production cost of biodiesel. The results were indicated in Fig. 4. With further increase in (vol./wt.) ratios at 3.6:1, the conversion efficiency went down gradually and stable at
3.8:1 ratio. According to the results which were presented in Fig. 4, 3.4:1 methanol to dry algal biomass (vol./wt.) is the most efficient in experimental process. With the methanol to algal biomass (vol./wt.) increasing from 3:1 to 3.2:1, the FAMEs yield increased considerably. The FAMEs content achieved is clearly the highest at 3.4:1 methanol to dry algal biomass (vol./wt.) ratio.

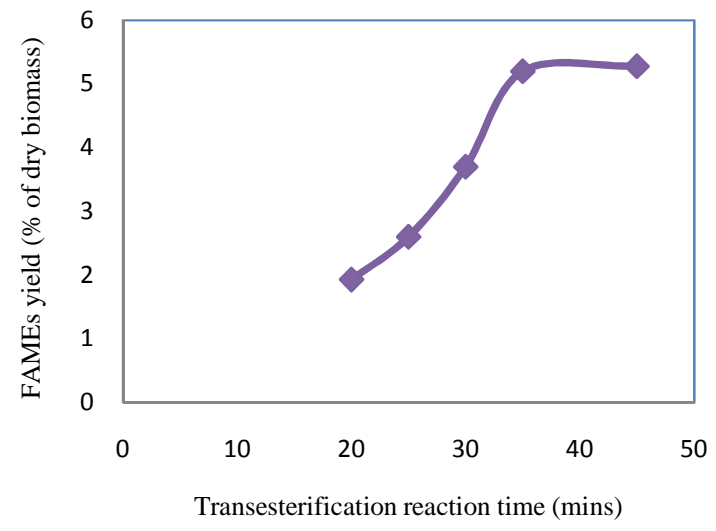

Fig. 3 - Effect of reaction time on algal biomass conversion efficiency. Under 3.4:1 methanol to dry biomass (vol./wt.) ratios, $0.6: 1$ catalyst to oil (vol./wt.) ratios at $75^{\circ} \mathrm{C}$.

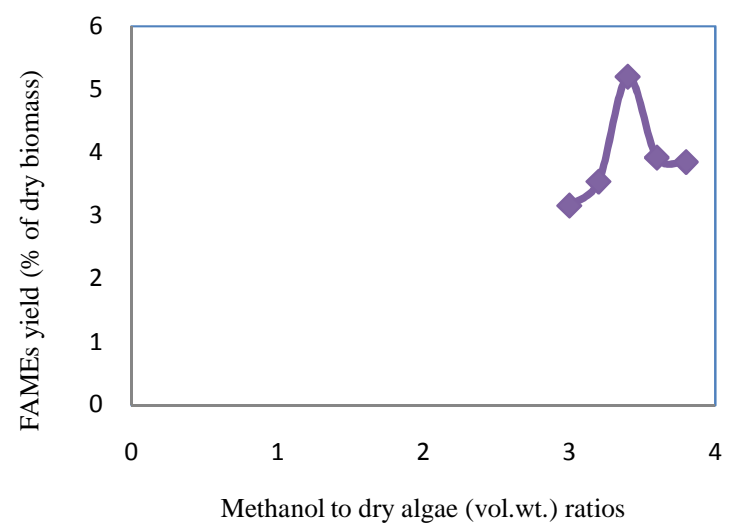

Fig. 4 - Effect of methanol to dry biomass (vol./wt.) ratios on algal biomass conversion efficiency. Under 0.6:1 catalyst to oil (vol./wt.) ratios at $75^{\circ} \mathrm{C}$ reacted in 35 minutes.

\subsection{Effect of catalyst loading}

The amount of catalyst which was used in the transesterification reaction is another important variable have effect on reaction rate. The FAMEs yields of biodiesel at different catalyst to dry algae (vol./wt.) ratios were presented in Fig. 5. The conversion efficiency is by far the highest (5.2\%) at 0.6:1 catalyst to dry biomass (vol./wt.) ratio. From the ranges less than $0.6: 1$ (vol./wt), the catalyst loading was not enough to complete the reaction, so that the FAMEs contents were significantly lower than that at 0.6:1 (vol./wt.) ratio. By contrast, the FAMEs contents also decreased while the catalyst to dry biomass increased. Addition of excess amount catalyst, gave rise to the 
formation of an emulsion, which increased the viscosity and led to the formation of gels (Xiangmei, 2008).

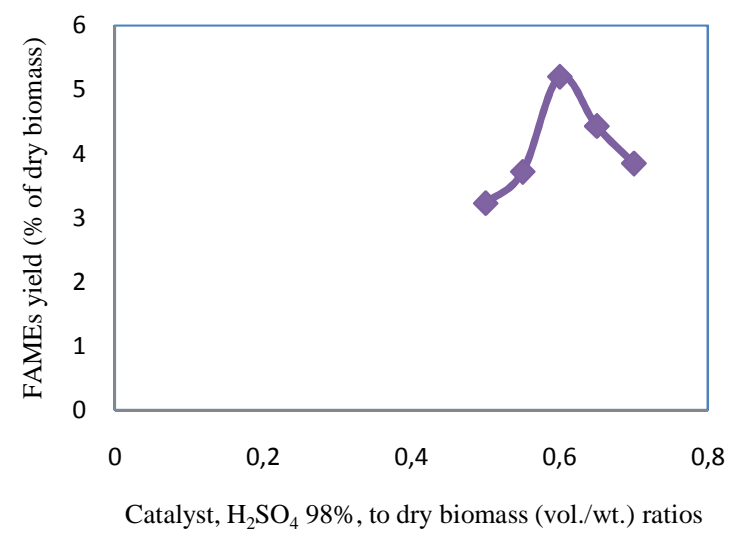

Fig. 5 - Effect of catalyst to dry biomass (vol./wt.) ratios on algal biomass conversion efficiency. Under 3.4:1 methanol to dry biomass (vol./wt.) ratios at $75^{\circ} \mathrm{C}$ reacted in 35 minutes.

\subsection{FAMEs analysis of biodiesel from microalgae}

The FAMEs in the hexane phase were analyzed using gas chromatograph equipped with a flame ionization detector. Calibration curves between peak area and concentration were established by injecting reference FAMEs samples of known concentrations into the GC - FID. The fatty acid composition of the lipid from microalgae throughout the extraction - transesterification was shown in Fig. 6. The analysis of biodiesel sample indicated the occurrence of significant amounts of the methyl ester of octadecatrienoic acid (C18:3), hexadecanoic acid (C16:2) and octadecadienoic acid (C18:2). The total amount of these methyl esters made up $77 \%$ of the total FAMEs yield.

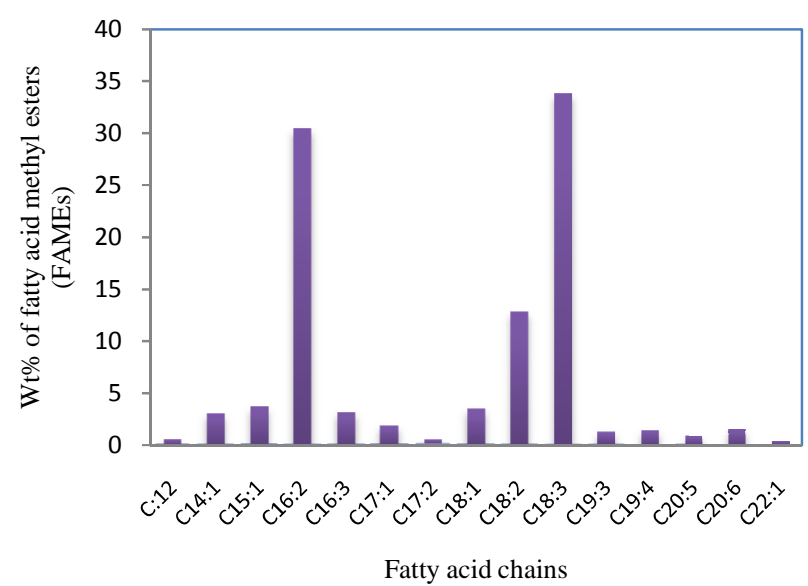

Fig. 6 FAMEs analysis of biodiesel obtained from microalgae through the extraction - transesterification method at $35 \mathrm{~min}$ reaction time, $75^{\circ} \mathrm{C}$.

\section{Conclusion}

Is has been demonstrated that biodiesel can be produced from algal biomass through the extraction transesterification method. The FAMEs yield from microalgae was found to be significantly affected by the independent effects of three factors investigated. Throughout these experiments, biodiesel of good quality can be produced from microalgae in the following reaction conditions: 3.4:1 methanol to dry biomass (vol./wt.) ratio with 0.6:1 catalyst loading to dry algae (vol./wt.), temperature at $75^{\circ} \mathrm{C}$ in 35 minutes. Analysis of the methyl esters by gas chromatography indicated that the methyl ester of octadecatrienoic acid (C18:3) is by far the highest content.

\section{References}

[1] B., Freedman, E.H., Pryde, T.L., Mounts. 1984. Variable effecting the yields of fatty esters from transesterified vegetable oil, J. Am. Oil Chem. Soc, 61:1638.

[2] Chisti, Y., 2007. Biodiesel from microalgae. Biotech Advances, 25(3): 294 - 306.

[3] Danielo, 0., 2005. An algae - based fuel, Biofuture (255).

[4] Grobbelaar, J. U., 2004. Algal biotechnology: real opportunities for Africa. South African Journal of Botany, $70(1): 140-144$.

[5] H., Fukuda, A., Kondo, H., Noda. 2001. Biodiesel fuel production by transesterification of oils, J. Biosci.Bioeng, 92(2001) $405-416$.

[6] Johnson, M., and Z., Wen. 2009. Preparation of biodiesel fuel from microalgae Schizochytrium lomacinum by direct transesterification of algal biomass. Energy and Fuels.

[7] Lewis, T., P. D., Nichols, et al., 2000. Evaluation of extraction methods for recovery of fatty acids from lipid - producing microheterotrophs. Journal of Microbiological Methods, 43(2): 107 - 116.

[8] Matxger, P., and C., Largeau. 2005. Botryococcus braunii: a rich source for hydrocarbons and related ether lipids. Applied Microbiology and Biotechnology, 66(5): $486-496$.

[9] Mondala et al., 2009. Biodiesel production by in situ transesterification of municipal primary and secondary slugdes. Bioresource Technology, 100:1203 - 1210.

[10] Schuchardt, U., Sercheli, R., Vargas, R.M., 1998. Transesterification of vegetable: a review. J. Braz. Chem. Soc. 9:199 - 210. 